to over-eat and drink wine at meals, and finally be. came an inebriate. Many cases are traceable where inebriety began at or before puberty, or after then subsided and later in life broke out again without any special causes. The expression "sowing wild oats" often describes a period of excessive use of spirits and nutritional disturbances, and then a full subsidence and a long period of temperate living. Far down in middle and later life a recurrence of this excess period appears again and often death follows. Here there is a persistence of nutrient and poison effects, which breaks out like some masked tire which has been dormant for a long time. The appearance of inebriety is usually sudden and without any exciting causes, and the change in conduct and manner of living is unexplainable. The same methods of using spirits and the same food impulses and tastes, and same surroundings as far as possible, appearing after a lapse of a lifetime, show that early defects are not affected by time. I conclude at this point with a summary of what I have intended to make clear in this study:

1. Inebriety is a most complex neurosis. The causes are equally complex, and include all the various states of degeneration which influence and disturb nutrition.

2. Obscure indigestion begins, and for this drugs and bitters containing alcohol are used. The narcotism which follows is so grateful that it is continued.

3. Dietetic delusions are fostered in the minds of parents and children, and from this many different forms of inebriety begin.

4. Often the most maniacal and chronic inebriates are from these delusional dyspeptics.

5. Starvation is present in many of these cases. The quality and variety of foods are deficient and defective nourishment follows.

6 . The uniformity of taking foods and the quality and variety are essential. This and nutritional rest and mental anxiety are important factors.

7. The inebriety following these conditions is successfully treated by elimination of the toxins and special correction of the nutrition.

8. Nutrition is a very active cause in the production of inebriety, and should receive a careful study in all cases.

DISCUSSION,

D. R. Brower, Chicago-I am pleased to have heard the admirable paper of my distinguished friend, Dr. Crothers. No man can speak with more authority than he can on the etiology and treatment of inebriety ; and what he says is as sensible as it is learned.

It is very gratifying to see so much interest being manifested by the profession on the subject of dietetics, for there is no more powerful agent in the causation and cure of disease. The recognition of the fact that imperfect digestion leads to auto-intoxication, and this to development of diseases of the nervous system, and the further fact that inadequate or im properly cooked food will produce the same result have been of much benefit to all concerned.

The publication far and wide of further facts that tea and coffee in childhood will develop a taste for stimulants that later along will produce inebriety, will save many from this dreadful state. The use of tobacco by the young may also be an important factor in this same pathogenesis.

Dr. Crothers (in closing)-The special object of my paper was to call attention to the injuries which always follow the use of alcohol in children. A very large amount of experimental evidence from the laboratory, in the use of alcohol on animals has been gathered for other purposes, which makes the facts conclusive. The disability and defects of children in all circles of life who have used spirits freely in childhood are to be seen in every town and country, I am pleased to most heartily agree with the speaker who preceded $m \theta$, in the statement of the skill in promoting the growth of animals, in fattening them, in developing their best qualities, so highly developed among stockmen and farmers, while the develop- ment of children physically through food channels, is totally neglected. We are on the frontiers of a new field of much important work, prominent of which is to clear away the deluslons which infest our conceptions of child growth and dietetics. One of these delusions is the food value of spirits and its harm. eseness. in early life. Our foreign population have strong views of alcohol or beer in childhood. Many others cling to the idea of stimulation and increase of vigor from spirits. These delusions must be overcome and a clearer conception of dietetics as a whole must follow, then we shall do with children what farmers do now with animals.

\section{TUBERCULOSIS: ITS HYGIENE AND DIETETICS.}

Presented to the Section on Physiology and Dietetics at the Forty-ninth Annual Meeting of the American Medical Association, held at Denver, Colo., June 7-10, 1898.

BY A. T. CUZNER, M.D.

GILMORE, FLA.

Tuberculosis in some form or other may fairly be considered the almost universal disease of man. "Schlenker made 100 consecutive postmortems on adults and children. He carefully examined every part of their bodies and found 65 per cent. tuberculous. In over 4000 successive postmortems made in Breslau in 1893, one-third of the bodies contained gross tuberculous lesions. If the microscope had been used, probably enough lesions could have been discovered to make 2500 infections. Babes fourd lesions of the bronchial glands in more than one-half of his postmortems on children. Biggs could demonstrate characteristic lesions in the lunge alone in 60 per cent. of his postmortems. Grawitz found primary tuberculous deposits in the lungs in 152 out of 221 cases, being nearly 70 per cent. of all infections. Loomis found the bronchial glands infective to rabbits in eight out of thirty bodies apparently free from tuberculosis during life."

Upon examination of the death records of thirteen prisons located in different parts of the country, we find the deaths from tuberculosis to be 59.9 per cent. Doubtless tuberculous deposits could be found in the 40.1 per cent. remaining.

In an article in a September issue of the Illustrated American, Prof. Fletcher W. Hewes publishes a dial illustrating the ratio of deaths in the United States from the most prevalent diseases. This is a reproduction of the dial.

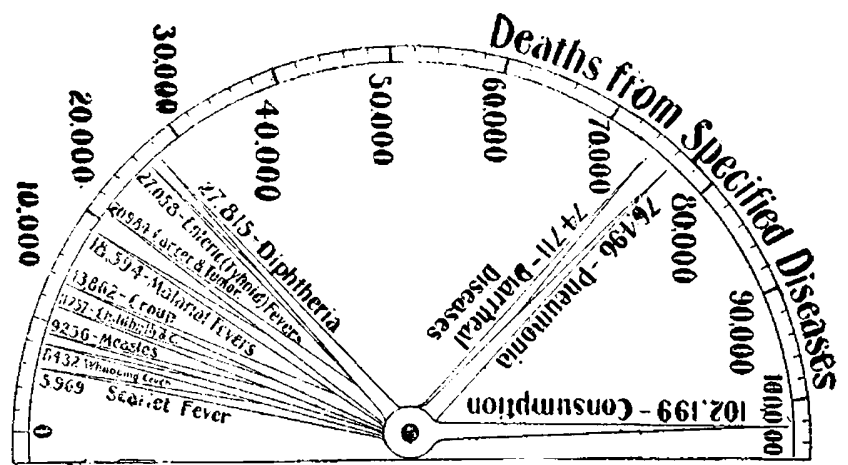

In proceeding with our investigation of this disease, it will be as well to consider as briefly as we can: 1 , the cellular pathology of the human tissues, and then in addition, what is known of the pathogenic germs thought by many to be the main cause of the disease: 2, the nature of tubercle, from which the disease takes its name; and 3 , the hygiene and dietetics of this complaint. 
CELLULAR PATHOLOGY.

Animal tissues are resolvable into an aggregation of morphologic units or cells, each having a life history of its own. At their death they are resolved into effete material, very deleterious to healthy cells, if retained in the tissues. Many tiasues when diseased become the home of minute forms of life-pathogenic bacteria. All cells are the result of the life of previous cells, "omne vivum ex ovo."

In the course of its development, every cell proceeds from the condition of a unit, in which it resembles every other morphologic unit, through a series of stages of gradually increasing divergence, until it becomes an element or part of a special tissue. The vital functions of the cell may be enumerated as follows: Contractility, irritability and automatism, reception of nutritive material and its assimilation, metabolism, secretion, excretion, and finally reproduction. All cells are sensitive to and influenced by their environment. They are repellent to deleterious influences in proportion as they possess that force or principle which we call vital. On the contrary, as they lack this force, they are open or subject to the invasion of disease. This may be in the form of toxins, or pathogenic germs, or both combined.

The healthy cells of animal tissues are antagonistic to the invasion of disease. All cells, whether of animal or vegetable origin, fulfill alike the law of their being; derived from a parent cell, they are nourished, develop, reproduce and die. During their life history they are favored or injured by their environment and circumstances over which they have but slight control.

Take, for example, cells of animal tissue exposed to contact with the atmosphere and subject to its vicissitudes, such as low temperature and sudden changes, their force (we call it vital) being reduced to a very low ebb for the time being; in contact with such cells is brought the ubiquitous microbe and there is at once inaugurated a conflict; which will come out victorious depends on various circumstances. If the animal cell has sufficient resistance, then the microbe is a failure. On the other band, should the vitality and resisting power of the cell be very low, and other circumstances favorable, then the microbe is rampant. This may be called the irrepressible conflict sung of by the poets.

\section{BACILLI}

Bacteria, microbes, schizomycetous fungi, are minute vegetable organisms causing the different known fermentations, and found associated with certain diseases, of which they are considered by many to be the cause.

"Bacteria in shape show three varieties-bacillus, pencil or rod; coccus, a ball, and spirillum, a corkscrew." Tubercle bacilli are in length one-half to one-third the diameter of a red-blood corpuscle, and their breadth is about one-fiftieth of their length. (See Fig. 1 в.)

\section{BACTERIUM}

There is a cycle of changes in the life of a bacterium that is shown plainly in the illustration. First, $a$, the spore is seen to lengthen to $b$, and forms a rod $c$. This by elongation and by fission produces more rods, $d$. These remain apart, $e$, or join together to form a chain, $f$. Some of the rods lengthen into filaments, $g$. These develop spores, $h$. The spores being set free, $i$, the series of changes begins again.
"For thirty-five years observers have noticed the bacillus of Koch living with the vinegar yeast. Botanists were divided in opinion whether they were inseparably a part of the life history of the mycoderma aceti, though nearly always found associated. Some botanists thought they were indispensable parts, and some thought not. They are the babies of the vegetations, and can be propagated as babies." (Ephraim Cutter.)

"I have long ceased to regard all the bacilli, micrococci and bacteria as the ultimate forms of animal or vegetable life. I look upon them as simply the embryos of mature forms, which are capable of propagating themselves in this embryonal state." (Salisbury-McNaughton's prize essay on Malaria.)

Microbes play a very important salutary part in the science of agriculture. They act as nitrogen suppliers to the soil. They are very useful to the dairyman, causing as they do that peculiar fermentation that renders cheese so palatable. They are ubiquitous. The air we breathe swarms with them. This is proved by Professor Tyndall. The food we eat, the water we drink, alike furnish them an abiding place.

The writer's view of the functions of the microbe is as follows: The cell formation of our bodies is constantly dying, as the life force leaves it and its work is done. The same principle holds good through-

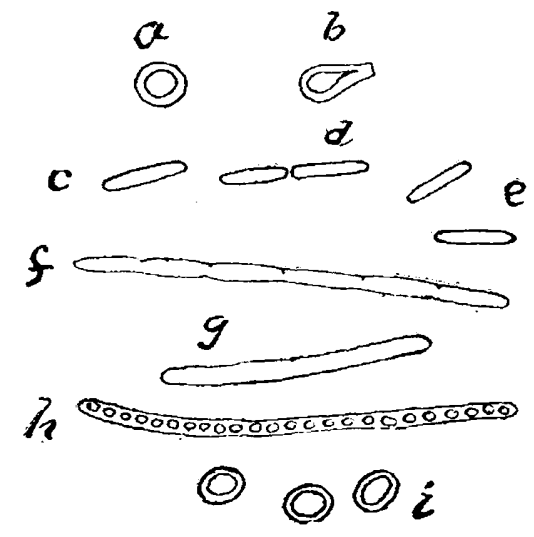

Fig. 1.--Bacterium.

out organic nature. All organic tissues undergo three distinct phases in their history-growth, decay and disintegration, and these three processes may go on simultaneously. In consequence of the dying of the cells, there is a continual accumulation of dead matter that must be disposed of by some process or processes. As one of these, the microbe gets in his work. Each microbe has his own particular work to do. In certain stages of tuberculosis we find more than one microbe associated with the disease. I do not think microbes deserve the ill repute in which they are held. When the human organism is diseased, microbes are found to be much more abundant, the dead matter to be changed and eliminated requiring much more work on their part. Like the buzzard, they are always ready to remove dead and offensive animal tissues. They also act as media of disease, just as flies do. They have likewise the power to impose upon the cell a certain amount of force, that tends to produce a condition most favorable to their disintegrating work.

Dr. Austin Flint admitted the importance of the tubercular bacillus in disease and, as quoted by Dr. H. B. Weaver, said: "You take away their lives, when you take away the means by which they live." Dr. Andrew H. Smith, quoted by the same write;, 
said, in speaking of phthisis: "The fact should be/deposition of tubercles in the cells and tubes of the recognized, that tubercle bacilli never become im- lung tissues, and the changes this material "suffers planted in the healthy system. There is always an and works." While this position has not been wholly abnormal anterior condition that should receive our abandoned at the present time, it is now considered attention. . . B By sufficiently improving the nutri- by a majority of the profession, that the tubercular tion, you lift the patient above the plane on which bacillus of Koch is the main predisposing and excithe bacillus flourished."

Solis-Cohen, also quoted by this same author, says: "To make our conception of the disease sufficiently comprehensive, we must include other eiements than the bacillus and the changes in cellular structure or chemic constitution of solids and fluids brought about by its activities. . . That condition which makes the human tissues a 'receptive soil,' a favorable 'culture medium 'for the tubercle bacillus--that condition which of old was called a 'diathesis' or 'susceptibility, 'is itself a disease, a departure from the norm, and I believe it to be the most important element in the morbid complexus termed tuberculosis.

It is the element requiring the greatest care in the prophylaxis, the most intelligent and faithful treatment."

Dr. Weaver says: "We believe this cachexia, this predisposition, which may be inherited or acquired, is a defective nutrition, superinduced by a want of vital energy, which has its correlative in the histologic expression, in the place of normal tissue, elements of abnormal condition and lowered vitality. We know that tuberculosis is not the product of a truly inflammatory process, neither is it a neoplasm, for it tends

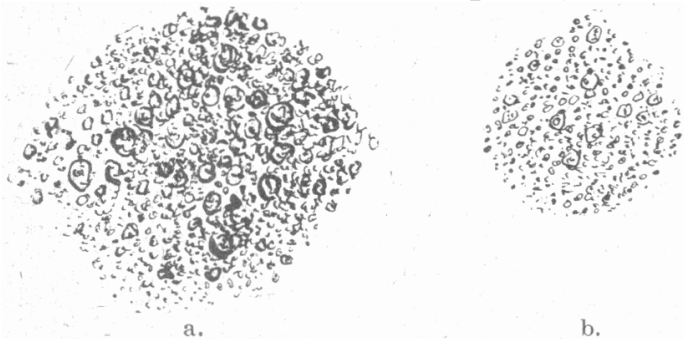

ting cause of consumption. The endeavors of the bacteriologist are, therefore, mainly directed to the destruction of the germs within the body and preventing access of fresh germs from without.

The following synopsis of tubercle is from the works of Charles J. B. Williams: "Tubercle presents the following characters: When first deposited it is a clear viscid, albuminous substance, becoming more and more solid by coagulation, as does fibrin, but differing from it in being incapable of organization. When more or less solidified it loses it transparency, becoming grey, yellow or drab. Uusually it is friable and of caseous consistence. Tubercle may be variously deposited in small, isolated points termed "miliary"; in granular masses, distinet or confluent; infiltrated diffusely into parenchyma; or aggregated in a mass, and enveloped by a cyst composed of surrounding tissues, thus constituting a tumor. T The formation of this substance is merely a perversion of nutrition.-Cuzner.] This is the commencement of the change to which the lowest forms of tubercle tend-that of maturation and softening."

Rokitansky thus describes the softening of tubercle: "After the tubercle has existed for some time in a state of crudity, it becomes, as it were, loosened in the textures, and breaks up on slight pressure and becomes more moist, then changes into a yellowish dissolving casein-like fatty and viscid matter. In the different changes in tubercular matter, as well as in the original deposition of this matter, the adjacent living parts have considerable share. A miliary tubercle from its first formation may become a cause of irritation to contiguous textures. The amount of

Fig. 2.-a, yellow tubercle; b, gray miliary tubercle.

neither to resolution and repair, nor to proliferation and persistence. It tendency is to destruction without subsequent repair. It is necrosed coagulation without blood-vessels, without cell organization, without life-it is death."

Dr. Weaver goes on to say: "Therefore, we conclude with Cohen, that when, in the course of ordinary wear and tear, or extraordinary wear and tear, or following inflammation or injury, or from any cause or combination of causes, degraded tissue elements have been produced, it is highly probable that the tubercle bacilli or other microbes, finding therein a favorable soil, modify by their activity the further evolution of the disease."

Consequently, in summing up the facts, as reflected by both observation and experience relative to the causation of tubercolosis, we think we are warranted in the following conclusions: 1 . Malnutrition is the starting point of tubercular process. 2, While the bacillus of Koch is, perhaps, the most important of the several microbes that influence the progress of the lesion in the various forms of the disease, yet it does not itself originate the disease in any form. 3 . Both factors-the dyscrasia and the bacillus - must exist in combination before there can be tuberculosis."

TUBERCULOSIS,

In the days of my student life, it was held and taught, that phthisis pulmonalis was caused by the this irritation and obstruction will depend on the natural excitability of the part, its functions, situations and size of tuberculous deposit."

The following is from the JounNaL, from the pen of John McFarlin, M.D.: "Tuberculosis is primarily an inflammatory process. Every tubercle begins its history as a single inflammatory node, not very different from those produced by the introduction of foreign particles in the tissues. In the early stages of the disease there is rarely any marked symptomic involvement, and many cases progress to the considerable destruction of organs before constitutional symptoms are observed. Up to a certain stage, therefore, tuberculosis is not essentially different from any ordinary or non-specific focal inflammation. It is as the disease progresses that the difference is observed; for as the cause of the disease is alive and engaged in growing and propagating its kind, there is a progressive tendency of the disease-producers to disseminate and new inflammatory foci to form; and, as growth means metabolism, there are waste products of the growth to be absorbed and eliminated.

"This is by no means all of the pathology of the disease. The tubercles develop at the expense of the organs whose tissues, transformed into or replaced by the tuberculous tissue, are unable to perform their functions or do these so insufficiently that disease must result from their incomplete action. Lastly, the tuberculous nodes, in which no blood-vessels are 
formed, constantly soften and disintegrate with the frequent formation of boles or cavities, in which, if they communicate with the outer air, saprophytic bacteria are likely to grow and the harmless, or oftener harmful, results of their metabolism are absorbed into the blood. Death is more often the result of destruc. tion of organs, suspension of vital functions from local lesions and profound secondary anemia, than from any poisonous principle in or produced by the brcillus."

\section{INEBRIETY AND TUBERCLLOSIS.}

Dr. T. D. Crothers, in an article in the April Jour NAL, on the subject, "Inebriety and Tuberculosis," says: "Alcohol acts on the body psychologically, physiologically and pathologically, and is literal paralysis and dissolution. No other substance known, in common use, has such profound destructive action on waste and repair of the body. This opens the door for many diseases by destroying the power of resistance and enfeebling all the powers of life." Speaking of inebriates, he further says: "In my experience

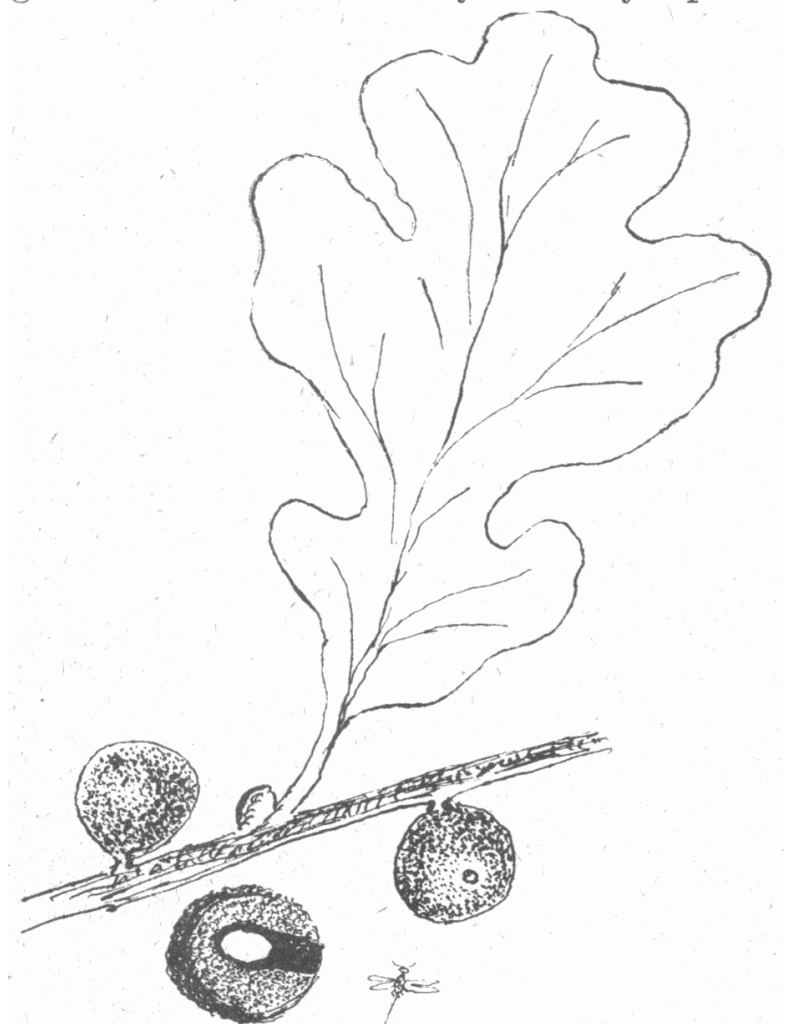

with 2000 cases, fully 20 per cent. are associated with tuberculosis." . . . "The use of alcohol results in deranged functions and disturbed energies. The two central processes of life-waste and repair-are affected, the first increased and the last diminished."

As we stated before: All cells are sensitive to and influenced by their environment. The microbe has the power to impress upon the cell a certain amount of influence that tends to produce a condition favorable to its disintegrating work. To illustrate how it is possible for one organism to influence another so as to minister to its wants, we will state the result of some studies we have made in natural history. We will examine a common gall called "oak-apple," the result of the puncture made by a small fly called "Cynips," of the order hymenoptera (see illustration). Galls are vegetable deformities or excrescences, due to parenchymatous hypertrophy, and according to the definition of Lucaze-Duthiers, comprise "all abnormal vegetable productions developed on plants by the notion of animals, more particularly by insects, whatever be their form, bulk or situation." The Cynips appear to prefer to puncture the limbs, twigs or leaves of the plants subject to their ravages, that are not possessed of as great a degree of force or ritality as the remainder of the plant. The influence of the puncture of these insects, or of the poison they inject, or of the egg they deposit by means of their ovapositors, or of all three combined, has such an effect on the infected vegetable tissue as to cause them to become hypertrophied and take on a further growth and development, by means of which the egg, larva and future fly are provided with a home and sustenance until such time as the fly is prepared to quit the gall. In addition to this (as will be seen in the illustrations from life) the grub and future fly are incased in an egg-shaped cell which is inclosed in a cavity in the interior of the gall. Leading from this cavity to the rind of the gall, so to speak, is a canal. In the ovoid cell in the interior of the gall, the grub is so placed that the future fly has its head always pointed toward the canal leaning to the exterior covering. When the fly is fully matured, it gnaws through the thin ovoid cell, and crawling through the canal until it reaches the exterior covering, punctures the same and escapes.

CAUSE OF DISEASE.

In summing up from the above examination, I think we may reasonably conclude that tuberculosis is a disease of malnutrition of the tissue elements of the body; that the bacillus, while it has considerable work to do and has great influence over the course of the disease, is not the prime factor or cause. We may further conclude from the vast clinical experience we have in evidence that there is no known germicide that is capable of destroying the microbes without causing destruction of the tissues or the life of the patient, and that all measures adopted in the past to destroy the bacilli have not obtained sufficient success to warrant us in looking in that direction with much hope for the future.

The bacilli, as we said before, are ubiquitous. If we destroy those in the body today, we have our work to do over again tomorrow. We can not continue indefinitely to act the part of executioners. Are we then to abandon the field as beaten scientists? Not while there is so much to encourage us in the clinical experience of the past.

Since writing the above, we read a curious account of the death of five out of the six Esquimaux Lieutenant Peary brought to the United States. They all enjoyed good health as long as the blubber they brought with them lasted. After it was all gone they began to pine, and successively became affected with coughs and lung troubles; finally they all died but one; this last was also expected to die, if not sent back to the arctic regions.

\section{CURABILITY.}

Notwithstanding the great mortality from the disease, overwhelming testimony is accumulating daily to the effect that if taken in its earliest stages, before the system is exhausted by its inroads, it can, and has been, cured in numerous instances. Again: Who that has made many autopsies but can testify to cicatrices found in the lungs, the result of the cure of a former tuberculosis? The late Austin Flint used to 
teach in Bellevue, over thirty years ago, that the disease was curable if taken in its earlier stages.

The following is from the pen of E. B. Borland, M.D., and is taken from the Journal. "Tuberculosis, uncomplicated with sepsis, may be considered a curable disease, in the sense that it may be held in abeyance, that is to say, kept in a latent condition for a lifetime, providing the vital resistance of the individual is kept up to the normal standard. Nature has been known to completely eradicate in a limited number of cases."

There are without doubt many more recoveries from tuberculosis than the average physician or the laity have any idea of. The postmortems of Schlenker, Babes, Biggs and Grawitz demonstrate this, as is shown in the begining of this article. It is a common belief that no one has consumption who does not die of it.

Continuing, Dr. Borland says: "The scientific physician will endeavor to imitate nature as far as he can interpret her methods. Investigations in search of an antitoxin have demonstrated that there is no immunity against tuberculosis when the three essential factors of infection, viz., debility, abrasions and bacilili are present. [If there is anything in the theory of immunity a child born of an infected mother ought to be less liable to infection, other things being equal, on account of its being almost constantly inoculated with toxins during intra-uterine life.-Cuzner.] The question arises, can tuberculosis in its latent stages be cured in all, to all intents and purposes? It has been demonstrated that two-thirds of all infections either disappear or remain quiescent during an average life. If nature can accomplish so much under the reign of empiric medicine, what will she be able to do when the physician concentrates all his energy on building up and maintaining the vital resistance of cell-life, and keeping septic germs, as well as tubercle bacilli, away from the latent infection?"

The following is also from the JournaL, by John Hey Williams, A.M., M.D.: "Eighteen years ago I was myself an invalid, suffering from supposed tuberculosis. I say supposed, having then no means of positive diagnosis. I was advised by such eminent authorities as Da Costa, Weir Mitchell and the lamented Pancost, that I could not live a year longer in Philadelphia, and that a change of climate was necessary. My attention was drawn to North Carolina by the writings of Hon. E. J. Aston and the reports of Dr. J. W. Gleitsman. A few months' residence in Asheville, and a more thorough knowledge of its climatic attributes, decided me to take up my residence there. With passing years came confirmed health, and I have remained eighteen years with pleasure and profit."

The careful reader of what has already been written, will doubtless arrive at the same conclusion as the writer, viz., that this disease is caused by, or is the result of, malnutrition of the tissues involved; that the microbe takes an active part in its manifes. tations, and that the disease is curable.

As to the treatment indicated: Shall we endeavor to destroy the microbe, and with this object in view continue to experiment with serum therapy, or shall we by a rational system of hygiene and of nutrition, build up and fortify the system against the inroads of the bacillus?

As to hygiene: There can be no doubt that an abundance of pure air and sunlight go a great way toward arresting this complaint, therefore those afflicted with this disease in its earliest stages, should by the advice and direction of their physician, seek that country where the largest amount of each can be obtained during the year.

\section{CLIMATE.}

There has been considerable difference of opinion, and much discussion as to the most desirable climate for preconsumptives. The writer prefers Florida as a place of residence for such, for the following reasons: 1 , in Florida there are more days in the year in which it is possible for a patient to be out in the open air and enjoy the sunshine, than can be found in any other State; 2, the climate and temperature are more equitable than in any other State. This is my personal experience of ten years, and is in accord with the reports of the U.S. Weather Bureau. However, each patient has idiosyncracies of constitution which render him or her a law unto themselves in this respect as to climate. Some patients do better in mountain air, while others receive much more benefit from a voyage on the ocean. Some are better served by a dry air, others by a moist one. I think it may be safely affirmed that the average individual but seldom uses over 75 per cent. of the air-vesicles, 25 per cent. remaining in a collapsed condition. These unused vesicles are prone to take on disease. I hardly need remind any one that failure to use means partial paralysis. Again, the object of respiration being to obtain a supply of oxygen to be used in the vital functions, any diminution of the supply means low vitality.

There is a very instructive article in the Medical World for October, 1897, of which the following is a synopsis: "Dr. W. F. Ball, Mountain Station, Ohio, writes that in 1851-2, he contracted a dry, hacking cough, with morning expectoration; had chills and hectic fever for months, and lost much flesh; was pronounced by several physicians as incurable. At this time an old Canadian doctor visited his father. ' He examined me thoroughly, and said there was only one way to save me, which was to carry out his in. structions faithfully. I was to sit up in bed and throw shoulders up and backward, filling the lungs with air to their utmost extent, until pain would warn me to stop; then to press down on the air to make it fill every cell. The closed cells, which were sealed by adhesions so that they could not be opened, were thus surrounded by healthy cells, and the diseased tissue would suppurate and be thrown off. It worked exactly as he told me. I have practiced these inhalations for over 40 years, and I can now, at the age of 62 years, expand my lungs to such extent as to in. crease my chest measure five inches, and I never have a cough to trouble me.",

HYGIENE.

It was formerly held that breathing the same air with a consumptive was highly dangerous. It is now believed that only the desiccated sputa breathed into the lungs is infectious. There can be mo doubt that a certain amount of morbid material is exhaled with each expiration. Carefully conducted experiments with the condensed moisture from crowdeet auditoriums prove this. Very highly offensive putrid albuminoid substances have been obtained in this way. Crowding consumptives into large sanitariums, in my opinion, is not good practice. Far better for such patients to live in homes by themselves and attend. ants. 
"Sunlight is nature's disinfectant, and experiments have shown that direct exposure to its rays for a few hours will destroy such germs as tuberculosis. The old method of exposing infected linen, carpets, etc., to the sun has thus been proven of value, and the rays of the sun must often destroy many of the bacteria present in infected hospital wards. This influence is also beneficial in destroying many of the bacteria deposited upon the surface of the earth, and even the upper layers of rivers must be somewhat purified by the agent." (Prof. A. C. Abbott, Philadelphia.)

The sputa should be received into paper receptacles to be afterward burned. We find in nature, that living beings, animals, plants, and living tissues, whether of animal or vegetable origin, are continually undergoing certain processes, viz: growth or development, decay or death. Both these processes go on simultaneousty. Professor Hammons says: "If we could perfectly adjust these so as to balance each other, man might live on forever." By a partial adjustment, we have increased the average longevity several years.

If the excreta of any kind are retained in the tissues, they produce disease, which is a slow form of death. If, after they are removed from such tissues, they are absorbed or applied to other living tissues they produce disease. If not thus absorbed such excreta undergo further change or decomposition when exposed to the action of heat and moisture in the open air, evolving during such process foul gases very injurious to life. But when placed in that great stomach of nature-Mother Earth-they are so digested that they are capable of becoming, by the absorption of different plants, parts of living organisms. In densely populated communities the sewerage system of disposal of excreta is adopted.

In an editorial in the London Lancet, the editor, in speaking of the sewerage system says: "After all, it is not a perfect success. Besides defiling the Thames to such an extent that the stench from it is quite perceptible, the gases that arise from the opening of the sewers at every corner, and are inhaled by the passersby, are largely the cause of the many cases of diphtheria and typhoid fever which exist in this city."

It is a query in my mind whether it may not be better for us to modify our plans of disposing of the excreta and waste material of cities; whether the sanitary laws adopted by the Jews under the instruction of Moses would not be better. We find that the Jews had their Geheuna, or hell fire located in the valley of Gi Hinnom, outside the walls of Jerusalem. In this fire was consumed all that was vile and likely to taint human life. Without discarding the sewerage system, might we not supplement it more fully than is done at present by the crematory system of disposal of all offensive substances? In the family this process might be more largely used. Let everything be burned in the stove that can not be passed down the sewers, or buried deeply in the ground, if they live in the country. Col. George Waring of New York states that "the foulest sewerage water passed through ten feet of clean sand comes out clean and pure." This brings us to the consideration of a water-supply.

\section{PURE WATER.}

It is very important that tuberculous patients should have an abundant supply of pure water. Water being a universal solvent of organic material, it is therefore very necessary that no filtration from closets or cesspools be allowed to contaminate the source of supply. I prefer and instruct my patients to drink large quan. tities of hot water, as I believe this promotes excretion of deleterious substances from the body, and adds to its functional activities. Frequent bathing of the body is of great use to patients. A sponge bath at night will often allay excitement and give patients rest.

\section{EXERCISE.}

Light exercise should be indulged in as far as the strength will permit, especially lung exercise. Many individuals with lung trouble have been cured by learning to play the cornet.

\section{DRUG THERAPY.}

Every qualified physician will administer such drugs to his patient as may be required by the particular phase the case may present from time to time. Before leaving the therapy of this complaint I will record my experience with those medicines we may properly call reconstructives; viz., nuclein, either Auld's or Vaughn's or the protonuclein of Reed and Carnrick. Either of these should be administered continuously for months, even after the patient has seemingly re. covered from the complaint. The administration of these preparations appears to be, to increase and im. prove the blood elements of the body.

\section{DIET.}

We now come to what, in my opinion, is the most important part of the treatment of tuberculous patients, viz., the diet. With regard to diet, it should largely consist of animal foods. Of these, eggs and milk should preponderate. I prefer to give eggs raw when tolerated. The albumin of the egg is similar to blood albumin, and is digested, or rather, it is absorbed into the blood without undergoing an elaborate digestive process. I have found the white of the egg mixed with water, tolerated when the yolk could not be borne by the stomach. Bone marrow of the ox is of greater value than cod-liver oil. Good creamery butter should be used freely, and to accomplish this result it should be spread thickly on very thin slices of bread. Heavy meals should be avoided, but food should be partaken of in small quantities between meals.

Beef feeding, as introduced by Dr. J. H. Salisbury, and largely practiced by Dr. Ephraim Cutter and others, is a wonderful power for good in the nutrition of consumptives. Beef-tea made from beef-extract, I consider positively injurious. It taxes unduly the excretive functions of the body, and has very little nutritive value. It is largely stimulating in its action. When I use beef-tea in my practice I have it prepared as follows: Take a small quantity of gelatin, say about one teaspoonful, and dissolve the same in a cup of hot water. When dissolved add a small quantity of extract of beef for flavoring and stimulating purposes, then add a little salt and pepper. Fruit should be partaken of freely. In fact, the aim of the physician should be, to endeavor by means of all the resources that the science and art of medicine has placed at his disposal to add to the digestive and assimilative powers of his patient, and thus give him or her the greatest chance for a cure of the diseased tissues. I might continue this subject of feeding indefinitely, but enough has been written to show its supreme importance. 